\title{
Assessing the impact of the tableware and other contextual variables on multisensory flavour perception
}

\author{
Charles Spence $^{1 * \dagger}$, Vanessa Harrar ${ }^{1 \dagger}$ and Betina Piqueras-Fiszman ${ }^{1,2 \dagger}$
}

\begin{abstract}
Currently little is known about how the non-edible items associated with eating and drinking (tableware items such as the plates, bowls, cutlery, glasses, bottles, condiment containers, etc.), or even environmental factors (such as the lighting and/or background music), affect people's perception of foodstuffs. Here, we review the latest evidence demonstrating the importance of these contextual variables on the consumer's behavioural and hedonic response to, and sensory perception of, a variety of food and drink items. These effects are explained by a combination of psychological factors (high level attributes, such as perceived quality, that may be mediating the effects under consideration), perceptual factors (such as the Ebbinghaus-Titchener size-contrast illusion and colour contrast in the case of the colour of the plateware affecting taste/flavour perception), and physiological-chemical factors (such as differences in the release of volatile organic compounds from differently-shaped wine glasses). Together, these factors help to explain the growing body of evidence demonstrating that both the tableware and the environment can have a profound effect on our perception of food and drink.
\end{abstract}

Keywords: Cutlery, Tableware, Contextual factors, Flavour, Liking, Multisensory, Weight, Colour, Size, Material

\section{Review}

Research on the topic of flavour perception has grown rapidly over the last decade or so (see Figure 1). In particular, the relative contributions of the various sensory cues (i.e., olfactory, gustatory, somatosensory, auditory, visual, and trigeminal) to multisensory flavour perception have been examined for a wide variety of different food and beverage items (see $[1,2]$ for reviews). While a number of recent studies have also highlighted the importance of atmospheric/environmental cues in determining what, how much, and how quickly, we eat and drink, and even how much we report liking the experience ([3,4]; for reviews, see $[5,6])$, far less research has studied the role of the tableware on eating, drinking, and flavour perception. Below, we review the latest evidence highlighting the significant effect that the non-edible components of eating and drinking (e.g., the cutlery, plateware, glassware, condiment containers, menus, and atmosphere) can have on

\footnotetext{
* Correspondence: charles.spence@psy.ox.ac.uk

${ }^{\dagger}$ Equal contributors

'Department of Experimental Psychology, University of Oxford, South Parks Road, Oxford, OX1 3UD, United Kingdom

Full list of author information is available at the end of the article
}

people's perception of, and response to, foods and beverages.

\section{Cutlery}

Cutlery, by which we mean forks, knives, and spoons, has been in widespread use for nearly 200 years now (e.g., $[7,8])$. Traditionally, it was made from a wide variety of different materials, such as wood, bone, ceramic, iron, brass pewter, etc. Nowadays, though, the range of materials used for cutlery is much narrower, mainly limited to stainless steel, silver, plastic, or wood (for chopsticks and the cutlery often found in ecofriendly coffee shops). This streamlining of materials has probably resulted from a combination of factors including: the ease and cost of manufacture/production, the ease of cleaning, environmental impact, and any taste transferred from the cutlery to the food.

Laughlin et al. [9] conducted what may well be the first published study to investigate whether spoons made from different metals have noticeably different tastes. They measured the metallic sensation (or taint) arising from spoons plated with seven different metals: Gold, 


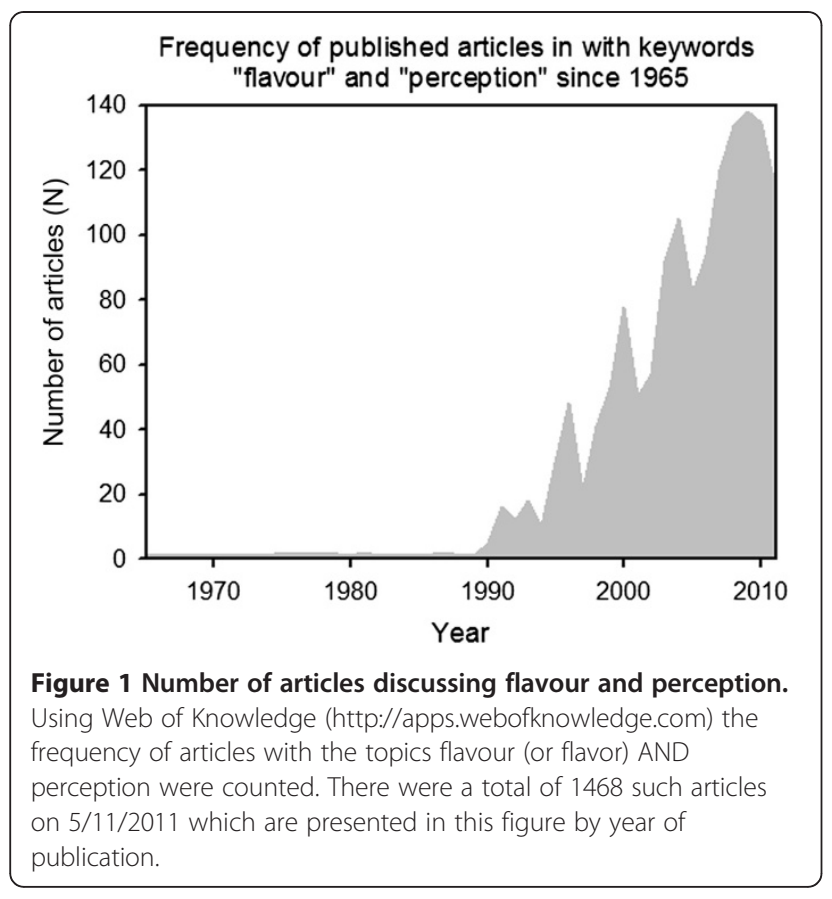

silver, zinc, copper, tin, chrome and stainless steel. Importantly, all of the spoons were identical in terms of their shape, size, and weight, and the visual differences between the spoons were not apparent to the participants (who were blindfolded throughout the study). The results revealed that spoons plated with different metals tasted distinctly different. In particular, the gold and chrome spoons were rated the least metallic, least bitter, and least strong tasting of all the spoons. By contrast, the zinc and copper spoons were rated as having the strongest, most bitter, and most metallic taste, and were also the only spoons that were rated as tasting significantly less sweet.

More recently, Piqueras-Fiszman et al. [10] extended this line of research by investigating the transfer of taste qualities from these plated metal spoons to the food consumed from them. The participants in their study had to evaluate sweet, sour, bitter, salty, or plain (i.e., unadulterated) cream samples using spoons that had been plated with one of four different metals: gold, copper, zinc, and stainless steel. Once again, the spoons had the same shape, size and weight, and participants were blindfolded in order to eliminate any visual cues. In addition to transferring a somewhat metallic and bitter taste to the food, the zinc and copper spoons were also found to enhance each cream's dominant taste (by as much as $25 \%$ in the case of bitterness). Surprisingly, the presence of a metallic taste did not influence participants' pleasantness ratings to any great extent (see Figure 2). Gold and stainless steel spoons, by contrast, did not affect the flavour of the different creams. Taken together, these results suggest that manufacturing spoons from a wider range of materials could, in the future, be used to enhance (or, at the very least, to alter) the bitterness, and/or other of the basic tastes of foods. That said, given that bitterness is not a gustatory attribute that is necessarily always appreciated by consumers (generally-speaking, most people tend to avoid bittertasting foods), the ability of cutlery to enhance bitterness might only be useful for a restricted number of foodstuffs (such as, bitter coffee and dark chocolate-based dishes/drinks). By contrast, the increased saltiness associated with eating salty foods with the aid of zinc and copper spoons could perhaps be expected to have a more widespread application (e.g., for people on restricted sodium diets).

In a related study, Piqueras-Fiszman and Spence [11] recently demonstrated that food was rated as significantly more pleasant, and perceived to be of higher quality, when tasted with a heavier metallic spoon as compared to a metallic-looking plastic spoon (in both cases, ratings were $11 \%$ higher for the metal spoon, see Figure 3). Given that both the weight and material properties of the spoons varied in this study, the independent contributions of each factor to the overall perception of the food eaten from them could not be disentangled. Piqueras-Fiszman and Spence suggested that the increased pleasantness ratings for the food tasted with the aid of the stainless steel spoon may have been attributable to the participants' perception that stainless steel spoons are of higher quality than plastic spoons. The participants' (possibly implicit) judgment regarding the quality of the spoon may then have been transferred to the food, causing it to be perceived as higher quality when eaten from a higher-quality stainless steel spoon. This account is very similar to Cheskin's [12] early notion of 'sensation transference'. While Cheskin himself was more interested in the transfer of sensations from food and beverage packaging to the product contained within, there seems to be no reason why the same principle could not be used to explain the observed transfer of properties from the cutlery to the food consumed from it.

To the best of our knowledge, the effects of cutlery on people's perception of food have so far only been tested with spoons. One might reasonably ask whether similar effects would also be observed for foods consumed with the aid of forks, knifes, and/or chopsticks? Since forks present a much smaller surface area to the mouth/ tongue, and knives are rarely inserted into the mouth (at least in polite company), they might be expected $a$ priori to exert less of an effect on the taste/flavour of food. Chopsticks tend to be manufactured from a fairly restricted range of materials (including cheap wood and plastic, lacquered wood, and the metal chopsticks that 

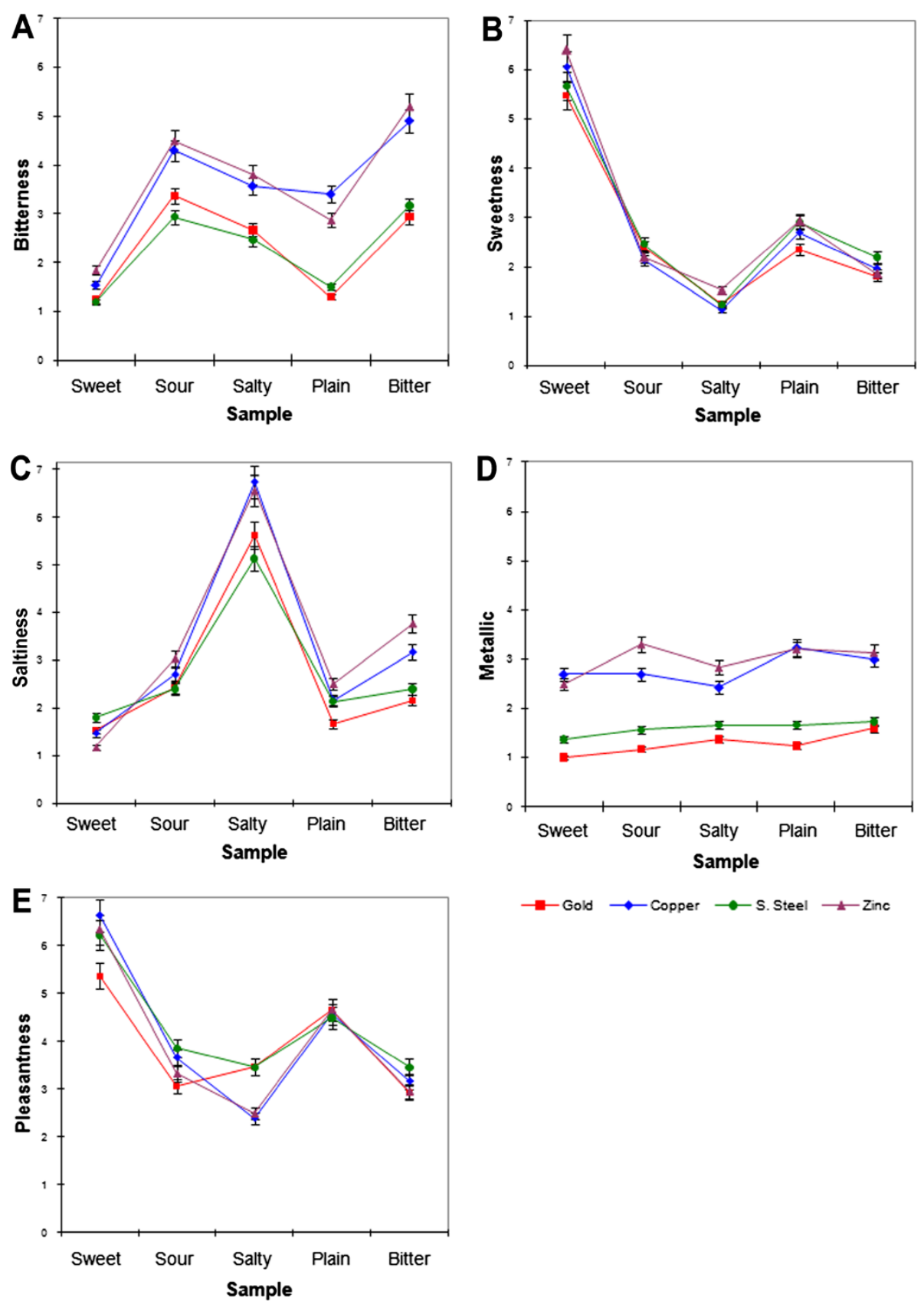

Figure 2 Representation of the mean ratings (on a 1 to 9 scale, where higher values indicate increased bitterness, saltiness etc) of each spoon and cream. A) Bitterness; B) Sweetness; C) Saltiness; D) Metallic; and E) Pleasantness. Vertical bars represent Tukey's HSD at $p<.05$. Source: [10].

are popular in countries such as Korea). It would therefore be particularly interesting for future research to determine whether or not the weight of the chopsticks (if not the material from which they are made) has any effect on people's perception of the taste/flavour of foods eaten with them.

In addition to the weight and material properties, the size of the cutlery also matters. Mishra, Mishra, and
Masters [13] recently demonstrated in a restaurant setting that the size of the cutlery can impact on how much people eat. They reported that those individuals who ate with the aid of smaller forks tended to consume more food as compared to those who ate with a larger fork. The researchers explained their findings in terms of "the goal of satiation". That is, when people go to a restaurant, the cost and effort involved in the dining experience 


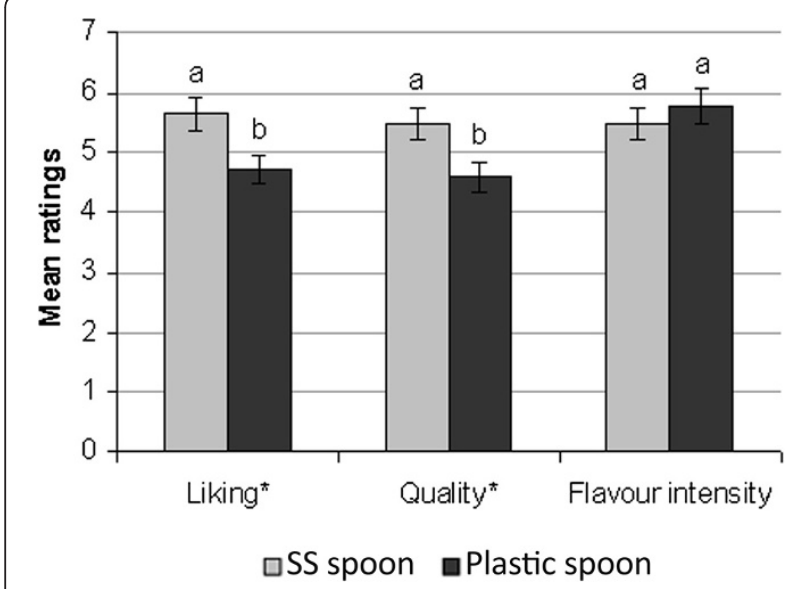

Figure 3 Participants' mean rating scores (liking evaluated on a 9-point hedonic scale; flavour intensity, and quality on unstructured $10 \mathrm{~cm}$ line scales, where higher values indicate increased liking, better quality, and more intense flavour); flavour intensity. Vertical bars represent significant differences, means with different letters are significantly different $(p<.05)$. *Significant effect at $p<.01$. Figure and text adapted from: [11].

causes them to demand an appropriate benefit - i.e., they want a greater number of forkfuls of food in order to satisfy their predetermined satiation goal. However, under laboratory conditions, where the participants do not have to pay for their food, Mishra and colleagues found that people ate less with a smaller fork than with a larger fork (that is, the opposite effect to that seen in the restaurant). In agreement with this hypothesis, Wansink et al. [14] observed that when offered free ice cream, participants who were given bigger spoons served themselves nearly $15 \%$ more than those with small spoons, though the effect did not reach statistical significance $^{\mathrm{a}}$. Thus, the amount that people consume is based on at least two factors: the size of the cutlery, and the cost/benefit analysis related to the cost of the food whereby people tend to eat less when the food is free and they are given a small utensil to eat with.

\section{Plateware or "Does the dish affect the dish?"}

Some years ago, Lyman [15] noted in passing in his book on the psychology of food that purple grapes don't look quite the same when served on blue plates. It is, however, only in the past year or so that such claims (specifically that the colour of the plateware may impact the taste/flavour of whatever foodstuff happens to be served from it) have been assessed empirically. In one study, Harrar, Piqueras-Fiszman, and Spence [16] had participants sample sweet or salty popcorn from four differently-coloured bowls: white, blue, green, and red. The participants reported that salty popcorn tasted sweeter when taken from a blue or red bowl, while the sweet popcorn was rated as tasting saltier when taken from the blue bowl (see Figure 4). Although these crossmodal effects were small (averaging a $4 \%$ change in participants' responses for a coloured bowl compared to the white bowl), they were nevertheless statistically reliable.

In another study, Piqueras-Fiszman et al. [17] compared the taste of foods served on either black or white plates. They found that a strawberry-flavoured mousse served from a white plate was perceived as $15 \%$ more intense, $10 \%$ sweeter, and was $10 \%$ more liked as compared to exactly the same dessert when served from a black (otherwise identical) plate (see Figure 5). Piqueras-Fiszman and her colleagues suggested that the colour of the plate may have affected the perceived colour of the food by means of colour contrast illusions. In the phenomenon of simultaneous contrast [18], a foreground object appears to have a different colour (or contrast) depending on the background colour $[19,20]$. According to such perceptuallybased interpretations, the colour of Piqueras-Fiszman et al.'s food would have appeared more intense against the background of the white plate than when served from the black plate. Thus, the perceived intensity of the food's taste/flavour might have been influenced by its perceived colour saturation which would have been influenced by the colour saturation of the plate itself.

\section{"Simultaneous color contrast suggests that foods can be arranged in combinations so that their colors are subtly enhanced, subdued, or otherwise modified. Yellow scrambled eggs on a yellow plate will look paler because of contrast. Purple grapes will look less purple on a purple plate and will look redder on a blue plate. A green salad will look less green on a green plate than on a plate that has no green in it. Red food on a blue plate will look more orange. Broccoli served with red fish will make the fish look redder, and slices of lime surrounding a grape mousse will enhance the color of both.” Lyman (1989, p. 112)}

That said, colour contrast cannot so easily be used to explain the effects of coloured bowls reported by Harrar et al. [16] because the popcorn was eaten by hand and would therefore likely always have been seen against a constant colour background (the participant's hand) just before being put into the participant's mouth. However, an alternative possibility here is that their effects demonstrate another example of sensation transference, given that red is typically associated with sweetness while blue is more often associated with saltiness [21,22,23]. As to where such colour-taste associations come from, consumers may simply be attuned to the statistics of the environment [21]; and/or to the packaging and product colouring typically used in the supermarket [23,24]. Evolutionarily-speaking, it would certainly make sense to be 


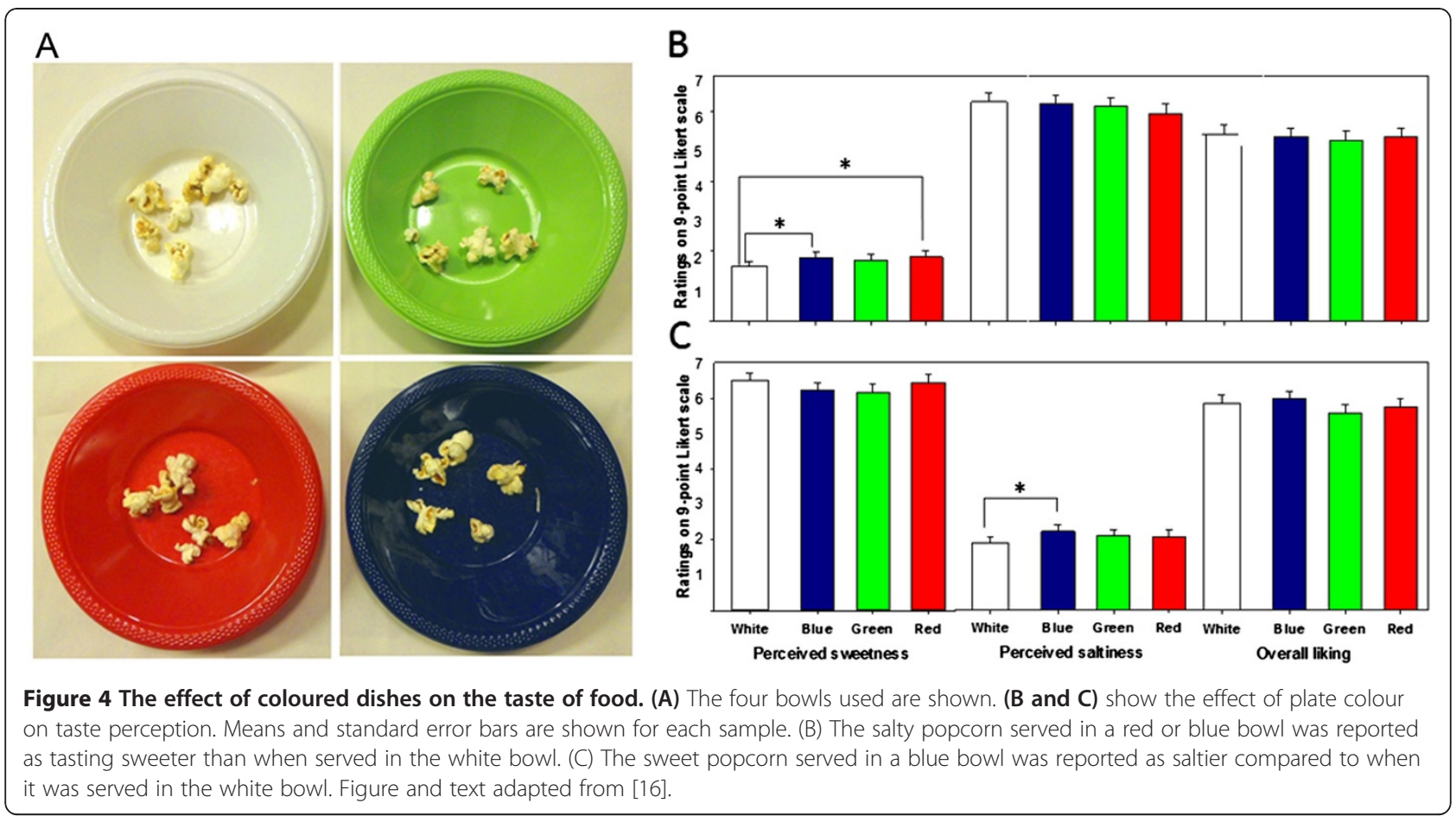

able to pick-up on the natural correlations that exist between colour and flavour in order to predict which foods would be riper, sweeter, and hence more likely to be rich in energy (imagine choosing fruit on a tree). Although explanations for the fact that the colour of the plate impacts taste/flavour perception have not been fully developed yet, these results will nevertheless hopefully make innovative chefs think a little more carefully about the colour of their

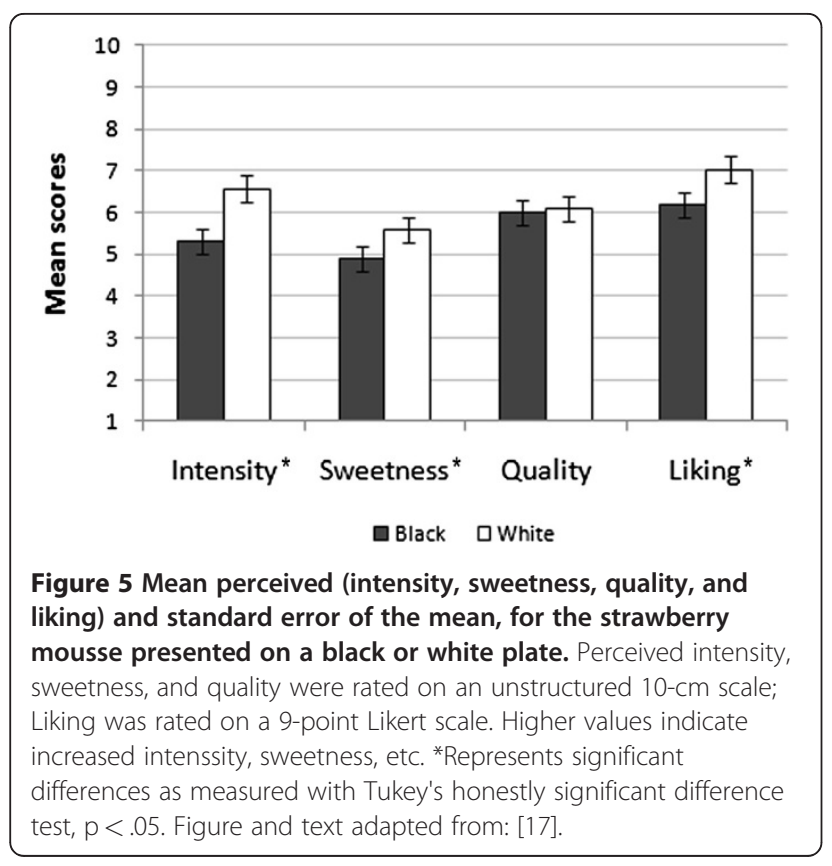

plateware and its potential effects on customers' flavour perception. $^{\text {b }}$

Piqueras-Fiszman et al. [17] also investigated whether the shape of the plate influences taste/flavour perception. They found that the taste of strawberry-flavoured mousse was not affected by the shape of the plate on which it was served. (The plates used in this study were square, round, and triangular in shape.) By contrast, Julie Simner (personal communication: "Yellow-tasting sounds? The cross-sensations of synaesthesia", $3^{\text {rd }}$ May 2011, Dept. Experimental Psychology, Oxford University, UK) has reported on a study conducted in collaboration with Jamie Ward and others in which they found that eating food from a round versus starshaped plate exerted a small but significant effect on the perceived sharpness of the food. What might explain the inconsistency in the results reported between these two studies? We would argue that the most likely explanation for these inconsistent findings relates to the fact that Simner et al. used a star-shaped plate (with 5 points), whereas Piqueras-Fiszman used triangular and square plates (3and 4-points) with fairly rounded edges at that. Thus, the angularity of the plates differed somewhat between these two studies (cf. [3]).

Here, though, it should also be noted that certain attributes of foodstuffs (such as their perceived sharpness, as in the case of cheese) may be more susceptible to being modified by the shape of the plate than are other taste/flavour attributes [25]. Since "sharpness" is originally a tactile property, one that is now used synaesthetically (or 
crossmodally [26]) in order to describe flavour attributes, it is possible that it may be more likely to exhibit sensation transference effects when used to describe foodstuffs. According to this argument, taste terms that have only ever been used to describe gustatory qualities (e.g., saltiness) may be less susceptible to the effects of sensation transference from the shape/haptic qualities of the plateware.

In addition to the effect of the colour and shape of the plateware on food perception, people are also influenced by the size of the plateware. So, for example, in one influential study, Wansink, van Ittersum, and Painter [14] investigated the effect of the size of the bowls on food consumption at a social event. When participants were given a larger bowl (34 oz) they served themselves over $30 \%$ more ice cream than those given a smaller bowl $(17 \mathrm{oz})$. Furthermore, since the participants nearly always finished the food in their bowls (as is apparently generally the case under self-serve conditions; [27]), those eating from a larger bowl ended up consuming more ice cream overall. Wansink and his colleagues attempted to account for these results in terms of the Ebbinghaus-Titchener size-contrast illusion and/or the Delboeuf illusion [28]. That is, they suggested that such visual perceptual illusions may have caused a given amount of food to be perceived as smaller against the background of a larger bowl, and as larger when presented in a smaller bowl instead [27].

However, it is important here to note that the effects of plate size on people's consumption behaviour are rather controversial. For instance, Rolls et al. [29] were unable to find a significant difference between the size of the plate $(17,22$, or $26 \mathrm{~cm})$ and the amount of food consumed at mealtime in three separate laboratory-based experiments. This discrepancy between the significant results reported by Wansink et al. [27] and the null results reported by Rolls and her colleagues may point to the existence of important differences between food consumption behaviours in the laboratory and those seen under more realistic consumption conditions (recall the discussion with spoons and the results of [13]). Rolls et al. tested consumption behaviour in the laboratory while Wansink et al. [14] had people fill out questionnaires at a company picnic (a real-world event) which may explain the differences. What is certainly true is that such differences should always be kept in mind when trying to generalise from the results of laboratory studies to real-world eating behaviours (e.g., [30]).

To summarise, the colour, size, and shape, of the plateware has now been shown to affect people's perception of the food placed on it. What about the other sensory attributes of the plateware. To date, only one study has examined the non-visual aspects of the plate. Piqueras-Fiszman et al. [31] explored whether the weight of the bowl from which participants tasted yoghurt would exert a significant influence on flavour perception. In their study, three bowls, identical except for the fact that their weights differed, were filled with exactly the same food (yoghurt). Consumers held each of the three bowls in their hand while rating the taste and flavour of the yoghurt on four scales. The yoghurt sampled from the heaviest bowl was rated as being 13\% more intense, 25\% denser, 25\% more expensive, and was liked 13\% more than the yoghurt sampled from the lightest bowl (see Figure 6). These results can perhaps be explained in terms of psycholinguistic transfer effects. Since weight properties are often used to describe the density of food (e.g., when we describe a food or meal as being 'heavy') the attributes that we associate with the heavier bowl may have been transferred (subconsciously or otherwise) onto the participants' perception of the qualities of the food in the bowl (cf. [32]). Furthermore, Piqueras-Fiszman and Spence [33] have now also reported the transfer of the sensation of "heaviness" onto expected satiety. They found that when exactly the same contents were presented in different containers, the yoghurt served in the heavier container was expected to be more satiating, even before the participants had a chance to taste it.

\section{Cups and glasses}

To date, far more research has been conducted on the perceptual and hedonic consequences of serving drinks in different cups and glasses than on the other elements of the tableware. Researchers have, for example, investigated the effect of varying the material, colour, and shape of the glass on the perceived aroma, taste, and flavour of wine (e.g., [33,34]; see [35] for a review). In one such study, Ross, Bohlscheid, and Weller [36] demonstrated that two red wines (a Syrah and a Pinot Noir) were more liked by a trained panel when tasted from a blue wine glass as compared to when served from a more traditional clear wine glass under normal whitelight illumination.

When it comes to the perception of the aroma, taste, and flavour of wines (both white and red) served from differently-shaped and -sized glasses, the results of the available research appear to be inconsistent. While the results of one study suggested that serving exactly the same wine in a different glass enhanced the perceived intensity of the aroma by as much as $150 \%$ (e.g., [37]), the results of another study failed to demonstrate any such difference (e.g., [38]). Can these seemingly contradictory results again be attributed to the lack of generalizability from laboratorybased experiments (where people are often deprived sensorially) and testing in more realistic environments? What differences in the experimental paradigm might account for the inconsistent results?

One possible explanation for the different results might be due to the different types of wine evaluated in 


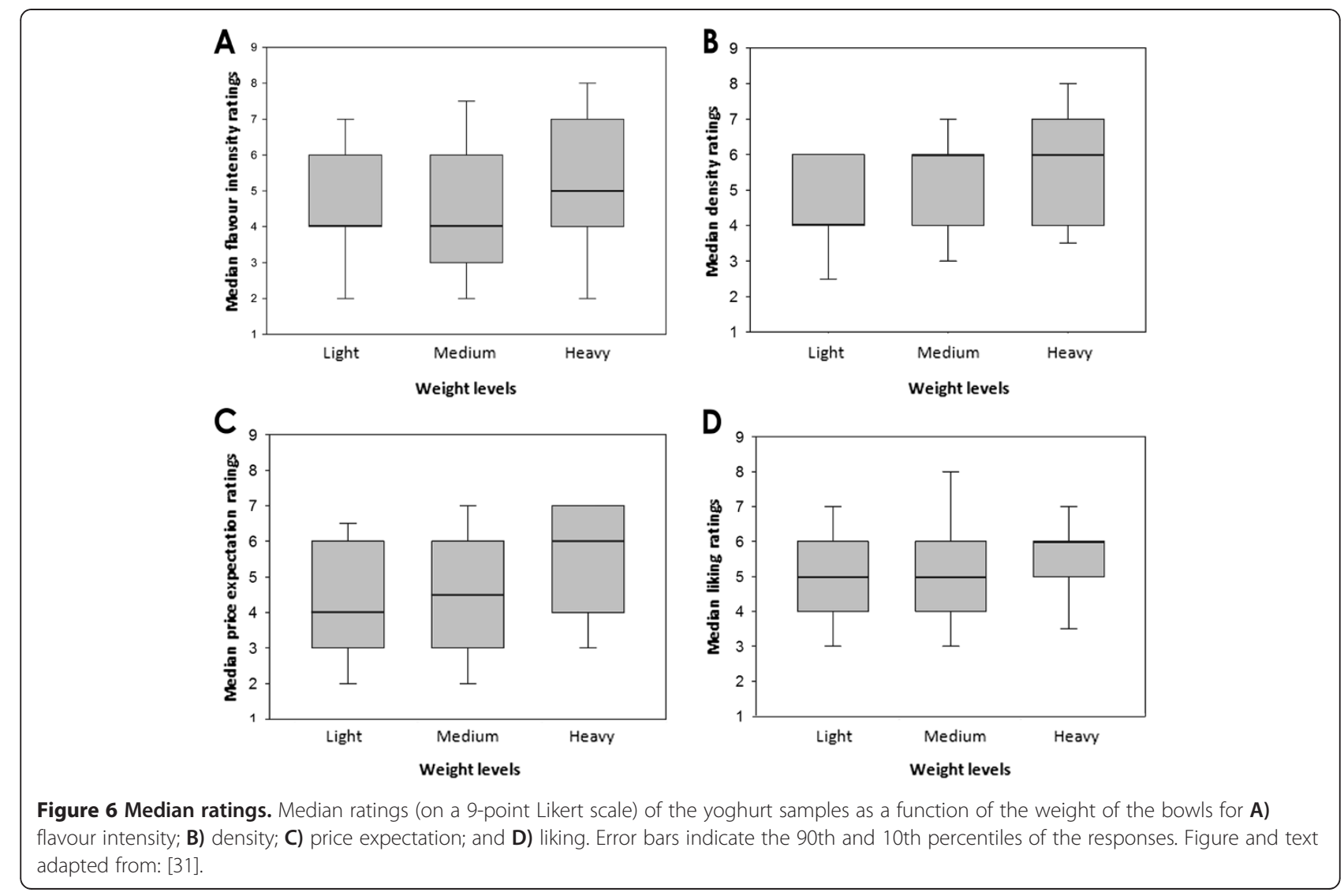

these studies, or the precise types/dimensions of the glasses used (which varied between each and every published study in this area). According to the more traditional physiological/chemical interpretation, different glass-shapes release different amount of volatile organic compounds from the wine's surface. That said, it has also been suggested by Emile Peynaud, one of France's leading wine experts, that the wine is directed to different parts of the tongue as a function of the shape of the glass [39]. However, such explanations cannot account for the results of these experiments in which all cues regarding the type of glass were removed $[33,40]$. In such laboratory based experiments in which the participant has no awareness of the particular glass, there appears to be no differences between the aromas of the wines served from, or stored in, different glasses. However, when a person has some awareness of the glass, either seeing the glass or, in the case of those experiments where participants have been blindfolded, holding it, the glass does appear to have an effect on their perception of the wine [35]. Thus, it would appear that the glass can affect the taste, flavour, and aroma of the wine, but only if the consumer has sufficient awareness of the physical properties of the glass. This obviously suggests more of a psychological interpretation for not of the results.
A sensation transference interpretation (as described above) would appear to fit this pattern of results since it critically depends on people being consciously aware of the kind of glass they are drinking from in order to transfer the attributes of the glass to the wine.

So far in this section, we have only examined research on the effect of the glass on the perception of a single drink, wine. However, one might expect that at least some of the findings that have been observed with wine should extend to other classes of beverages as well, such as perhaps coffee (given that certain coffees contain as many as 50\% more volatile organic compounds than do many wines).

Schifferstein [41] found that participants' responses to various attributes of drinks (tea and soft drinks) depended on the type of cup used. Meanwhile, Guéguen [42] has also reported that $47.5 \%$ more people perceived identical soft drinks as being more thirst-quenching when consumed from a "cold coloured" blue glass as compared to a "warm-coloured" yellow glass (only 15\% perceived the drink from the yellow glass to be more thirst-quenching). Similarly, Krishna and Morrin [43] have demonstrated that water samples served in flimsy plastic cups are perceived as being of higher quality ( $\sim 8 \%$ higher) when participants were not able to touch or hold the cup compared to when they were. Here 
again the concept of sensation transference can be used to account for the observed effects; be it the "cold" from the colour of the cup or the "cheap" from the material properties of the cup. Each time, the attribute (be it sensory, emotional, or evaluative) of the tableware appears to be transferred from the cup (cutlery, or plateware) to the food or drink.

\section{Bottles and condiment containers}

Thinking of condiment containers (e.g., ketchup bottles), people have very specific associations regarding the shape and materials of such bottles, which might influence their perception of food and drinks (see [44] on the concept of image molds in product packaging). Although it is certainly true that people normally do not eat directly from such containers, they might nevertheless exert an effect on the consumer's overall dining experience, affecting people's eating behaviours, and ultimately even their perception of the food and drink.

For example, Dan Ariely [45] reported that changing the containers for coffee paraphernalia (i.e., the sugar bowl, the milk flask or jug, the cinnamon and chocolate shakers, the stir-spoons) exerted a significant influence on people's liking for coffee. In this study, participants were offered a cup of coffee in return for filling in a questionnaire. For some participants, the containers were made of glass-and-metal, set on a crushed metal tray, and accompanied by silver spoons and nice labels. For others, the very same condiments were placed in Styrofoam cups instead and labelled by hand using a felt-tipped pen. The participants who took part in this study reported a preference for the coffee served with higher quality condiment containers and were willing to pay more for their coffee. As Ariely puts it: "When the coffee ambience looked upscale, the coffee tasted upscale as well" (2008, pp. 159-160).

The perceived quality of the accessories could potentially also be improved simply by changing their weight. Given that the weight of the bowl was shown to affect the flavour of the food (see [31], described above), one might also expect heavier condiment containers to improve the perceived quality of the food [33].

What about for salt and pepper shakers? It turns out that the size of the opening affects people's consumption of salt and pepper. The bigger the holes in the salt shaker, for example, the more salt people consume [48]. Similarly, even the location of the shakers on the table (i.e., the ease of access) has also been shown to influence people's behaviour. Here it is important to note that ease of use is also important in container/packaging design. Apparently in homes where EZ Squirt plastic ketchup bottles (with a conical nozzle) are used rather than the traditional glass bottle, ketchup consumption can increase by as much as $12 \%$. It has been suggested that this might be related to the fact that EZ Squirt bottles are easier to use by young children, one of the most frequent consumers of this particular product [49]. Taken together, the results reported in this section demonstrate that people's consumption behaviours can be impacted by the location, ease of use, and perceived quality of condiment containers at the table.

\section{Atmosphere}

The environment in which people eat is known to influence many aspects of consumption behaviour, from what people choose to order, to how much they are willing to pay, and how quickly they eat/drink. Much of this research has focused on the atmosphere in restaurants and in the home (e.g., [5,6,50,51,52] for reviews; [3,4,53,54]). Coelho et al. [55] have recently reported that exposure to chocolate-scented lotion increased the intake of chocolate-chip cookies (by approximately 75\%) when the lotion was labelled as "chocolate-scented" in comparison to the same lotion when it was unlabelled. Beyond the scent, the lighting can also affect the perception of food and drinks. Oberfeld et al. [4] investigated the effect of the colour of the lighting (white, blue, red, or green) on people's perception of the flavour of a Riesling (white) wine. Importantly, since the wine was served in an opaque black wine glass, the lighting did not affect the colour of the wine itself. Nevertheless, people reported liking the wine significantly more (and were willing to pay nearly $50 \%$ more for it) when they tasted it under blue and red lighting rather than under green or white lighting. Oberfeld et al. also noted that blue and green lighting made the wine taste spicier and somewhat fruitier, while the same wine evaluated under red lighting was rated as $50 \%$ sweeter than under blue or white lighting.

In terms of more extreme variations in the lighting conditions, Scheibehenne et al. [56] reported that eating in the dark decreased people's ratings of the acceptability of food and their likelihood of future consumption [47]. Gal et al. [3] also reported that brightness of the lighting affects pleasantness and the overall consumption of coffee. In their study, Gal et al. varied the lighting in a room and investigated its effect on people's consumption of coffee. The lights were either bright or dim - the idea being that bright lighting should, if anything, make the coffee taste stronger. The 135 undergraduates at a North American University who took part in this study were seated in a room and given a Styrofoam cup containing $5 \mathrm{oz}$ of freshly brewed coffee to drink. In one condition, the room was illuminated by two 500-watt halogen lamps, whereas in the other condition, it was lit by only a single 60-watt incandescent bulb instead. The participants were asked about their preference for coffee strength, and after they had finished filling in some 
forms, the amount of coffee that they had consumed was determined. Those people who reported liking stronger coffee (i.e., those falling 1.5 or more standard deviations above the mean) drank more coffee than those who reported a preference for weak coffee (i.e., those who fell 1.5 standard deviations or more below the mean). More importantly, those who reported liking strong coffee drank significantly more of it under bright rather than dim lighting conditions, whereas the reverse was true for those who preferred weaker coffee. Crucially, the lighting level had no direct effect on people's estimates of the strength of the coffee itself (i.e., when looking at it without actually tasting it). Taken together, these results demonstrate that both the intensity and colour of the lighting in a room can affect people's perception of the flavour of, liking for, and even their consumption of, drinks such as wine and coffee.

In addition to olfactory cues and lighting, auditory stimuli can also affect the environment and influence people's consumption behaviour, their preference ratings, and even their rating of a food's flavour. When music is used to set-up a particular ethnic context, in a restaurant, it can make food flavours appear more authentic [57]. Hence, playing French music is likely to enhance the perceived "Frenchness" of the food and eating environment. Spence and Shankar [6] recently reviewed the research on auditory influences on food perception and revealed a variety of sounds (music, food-crunching sounds, and even pure tones) can have systematic effects on our perceptions of food and drink. These authors highlighted a number of potential explanations for these crossmodal effects including multisensory integration, attention, associative learning, and the setting-up of sensory expectations in the minds of consumers.

According to the attentional account, if the background music in a restaurant happens to capture a customer's attention, then they may not devote as much of their processing (i.e., attentional) resources to the in-mouth sensations and hence the sound might detrimentally affect their perception of the foodstuff [see 58]. Meanwhile, other researchers have suggested that loud noise/music may simply "mask" taste perception [59], although it remains something of an open question as to whether the phenomenon of crossmodal masking actually exists [60]. Another possibility is that music influences the perceived passage of time which may, in turn, impact how much one eats. In other words, if the music makes one feel that less time has passed then one may want to stay longer in a particular restaurant or bar, and hence eat or drink more as a result [61].

In summary, the results reviewed in this section demonstrate how profoundly the sensory attributes of the environments in which we choose to eat and drink can impact on our food and drink-related behaviours/perception. Note that all of the studies mentioned in this section involve researchers manipulating a single sensory attribute of the environment at any one time (i.e., just the lighting, just the music, or just the scent). Future research will need to consider how different sensory cues interact in multisensory environments (e.g., when the lighting, music, and scent are manipulated simultaneously; see [5]).

\section{Menu: pricing and naming}

Menu names are particularly important for setting-up certain sensory expectations for the diner [62]. For example, it has been shown that people assume that an ice cream named 'Frosh' will be creamier, smoother and richer than an ice cream named 'Frish' [63]. It is believed that this effect is driven by the sound of the vowels in the two names [see also 25 for a review]. How food names, and the subsequent food expectations that they may elicit, relate to ratings of food pleasantness has been investigated by Martin Yeomans and his colleagues in Sussex [64]. In one of their studies, three groups of participants were given the same red coloured frozen food to taste. One group of participants was given no information concerning the dish, another group was told that it was a frozen savoury mousse, and a third group was told that the dish was labelled 'Food 386'. The participants who were given no information appear to have expected the dessert to be something like a sweet strawberry ice cream (given the colour). Instead, what they got was a savoury salmon mousse. This group of participants disliked the food more than the other two groups of participants, and rated it as tasting saltier than the other groups as well. When subsequently offered some of the same food a few weeks later, the uninformed group ate less (if any) than either of the other two groups. Yeoman and colleagues' results clearly highlight the importance of menu labelling in terms of creating the appropriate sensory expectations, and avoiding the possibility that a food does not meet a customer's prior expectation (disconfirmation of expectations see also $[65]^{\mathrm{C}}$ ).

Similarly, menu names can affect the perceived ethnicity of a dish and the rate at which people order the different dishes. Meiselman and Bell [66] manipulated the recipes and the dish name of four pasta samples to study these effects on the perceived ethnicity and pleasantness of the pastas by British consumers. The addition of an Italian name was found to significantly increase perceived Italian ethnicity of the dish and lowered its perceived "Britishness", whereas the pleasantness of the food was more influenced by changes to the recipes than by changes to its name on the menu. Bell et al. [67] replicated the effect of changing the name [66], and extended their results by looking at the effects of atmosphere in a restaurant. Italian and British foods were offered in a British-styled or in an Italian-decorated eating environment. The Italian theme was associated with an 
increase in the selection of pastas and dessert items, and a decrease in the selection of trout (see Figure 7).

In addition to the name of the menu item being important, Wansink, van Ittersum, and Painter [68] have reported that the text used to describe a food item on a menu can affect its appeal. They found that menu items with more elaborate descriptions were rated more favourably (more positive comments about the food, more appealing, tastier, and perceived to have a higher caloric content) than their identical (but simply-named) counterparts. How might the price of items on a menu affect the perceived quality and enjoyment of the item? Based on differences found for text read off of a heavy versus a light clipboard [32], it might be predicted that the weight of the menu would affect whether one thinks that the prices are appropriate; the heavier the menu the more appropriate a higher price would seem to be. An interesting area for future research would be to see if people are more likely to choose the more expensive item from a heavier menu as compared to a lighter menu (think of the heavy wine menu as compared one often finds at certain top-end restaurants). While effects related to the weight of the menu, and it's relation to price, are fairly speculative at the present time, the effect of the name and description of food in menus has been tested empirically. Food descriptions on a menu can make the item appear more expensive (such as menus that specify that ingredients are organic, or "grade A" beef; [69]). The consumer might well believe the food item to be of higher quality, and hence enjoy its taste/flavour that much more (see [70], for a review; [71]).

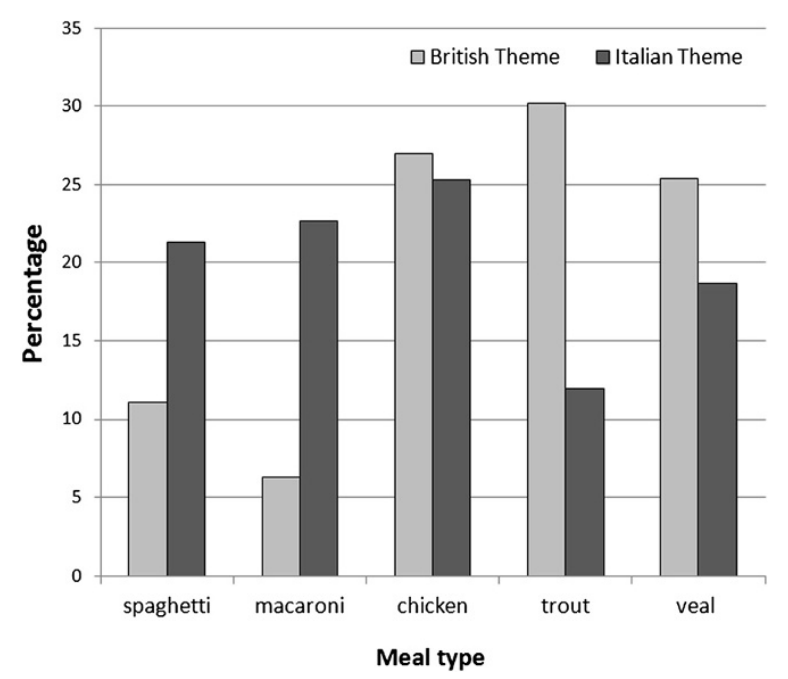

Figure 7 Effect of atmosphere on food choice. Percentage of customers who selected each dish plotted based on the theme of the room (Italian vs. British). Figure and text adapted from: [67].

\section{Conclusions}

The results of the research outlined here clearly demonstrate that the tableware, and the other non-consumable elements of the table setting, can all exert a significant effect on our perception of, and behaviour toward, food and drink. In terms of understanding these effects, there appears to be a number of potentially relevant psychological and physiological explanations for the effects that have been documented. Sensation transference might, for example, partially account for the fact that properties of the tableware are associated with the food and drink [12]. High-level attributes of the accessories, such as their perceived quality and expense, might be transferred to the consumables, just as low-level attributes (such as colour) seem to be $[16,17]$. Similarly, psycholinguistic transference might result in descriptions of cutlery, plates, cups, or decorations being transferred onto the food (e.g., a "heavy" bowl results in the perception of food that is rated as being heavy).

There are also visual perceptual effects that might clarify some of the above-mentioned influences of vision on food perception [72]. Colour contrast, for example, might help to explain why food served on a white plate might taste stronger than the same food presented on a black plate. The Ebbinghaus-Tichener size-contrast illusion or the Delboeuf illusion could explain why the same amount of food is perceived as more filing when eaten from a small bowl compared to from a larger bowl.

Finally, there is some evidence for physiological/chemical changes to the food and drinks as a result of the shape or material of the tableware. For instance, certain glass shapes will presumably release more organic molecules from wine than other glass shapes [38]. However, this review suggests that it is a drinker's (or taster's) awareness of the glass shape and size that appears to be crucial in order for the shape/size of the glass to affect the aroma and flavour of the wine [35]. Similarly, spoons made from different metals might taste different because they interact with foods (probably differently depending on the properties of the food item itself, and the material of the spoons, such as their $\mathrm{pH}$ or temperature).

Although this field of research is relatively new it is undoubtedly growing rapidly. Already, there is evidence for effects of tableware and accessories on eating and drinking which probably reflect a combination of perceptual illusions, psycholinguistic and sensation transference effects, and physiological/chemical phenomena. It seems, therefore, reasonable to suggest that both the food industry and home-dining should pay far more attention to the tableware and atmosphere in order to maximize the dining experience.

\section{Endnotes}

${ }^{a}$ One can certainly think of the transfer of taste/flavour from plate to mouth as equivalent to previous research 
showing that the colour of product packaging can also influence the taste/flavour of the contents [24,47].

${ }^{\mathrm{b}}$ It is worth noting that the effect of the spoons observed in [13] and [14] do not necessarily conflict with one another. Importantly, there were several methodological factors that were predicted to give rise to different results in these two studies: the food was presented differently (already served on the plates vs. self-service, respectively) and the contextual conditions were different (real restaurant vs. invitation to attend a social event).

${ }^{c}$ These effects have been extensively documented in the branding/packaging industry (e.g., $[73,74])$.

\section{Competing interests}

The authors declare that they have no competing interests.

\section{Authors' contributions}

$\mathrm{CS}, \mathrm{VH}$, and BP-F contributed equally to this review. All authors read and approved the final manuscript.

\section{Acknowledgements}

Vanessa Harrar holds the Mary Somerville Junior Research Fellowship of Somerville College, Oxford University. Betina Piqueras-Fiszman holds a scholarship from the Ministry of Education, Spain.

\section{Author details}

'Department of Experimental Psychology, University of Oxford, South Parks Road, Oxford, OX1 3UD, United Kingdom. ${ }^{2}$ Department of Engineering Projects, Universitat Politècnica de València, Camino de Vera, s/n, Valencia, 46022, Spain.

Received: 7 October 2011 Accepted: 23 December 2011

Published: 2 May 2012

\section{References}

1. Auvray M, Spence C: The multisensory perception of flavor. Conscious Cogn 2008, 17:1016-1031.

2. Stevenson RJ: The psychology of flavour. Oxford: Oxford University Press; 2009.

3. Gal D, Wheeler SC, Shiv B: Cross-modal influences on gustatory perception:; 2007. http://ssrn.com/abstract=1030197

4. Oberfeld D, Hecht $H$, Allendorf U, Wickelmaier F: Ambient lighting modifies the flavor of wine. J Sensory Stud 2009, 24:797-832.

5. Spence C: The ICI report on the secret of the senses. London: The Communication Group; 2002

6. Spence C, Shankar MU: The influence of auditory cues on the perception of, and responses to, food and drink. J Sensory Stud 2010, 25:406-430.

7. Himsworth JB: The story of cutlery: From flint to stainless steel. London: Ernest Benn Ltd; 1953.

8. Visser M: The rituals of dinner: The origins, evolution, eccentricities, and meaning of table manners. London: Penguin; 1991.

9. Laughlin Z, Conreen M, Witchel HJ, Miodownik MA: The use of standard electrode potentials to predict the taste of solid metals. Food Qual Prefer 2011, 22:628-637.

10. Piqueras-Fiszman B, Laughlin Z, Miodownik M, Spence C: Tasting spoons: assessing the impact of the material of the spoon on the taste of the food. Food Qual Prefer 2012, 24:24-29.

11. Piqueras-Fiszman B, Spence C: Do the material properties of cutlery affect the perception of the food you eat? An exploratory study. J Sensory Stud 2011, 26:258-262.

12. Cheskin L: How to predict what people will buy. New York: Liveright; 1957.

13. Mishra A, Mishra H, Masters T: The influence of the bite size on quantity of food consumed: a field study. J Consumer Res 2011, 38.

14. Wansink B, van Ittersum K, Painter JE: Ice cream illusions: Bowl size, spoon size, and self-served portion sizes. Am J Preventive Med 2006, 31(3):240-243.

15. Lyman B: A psychology of food, more than a matter of taste. New York: Avi, van Nostrand Reinhold; 1989
16. Harrar V, Piqueras-Fiszman B, Spence C: There's more to taste in a coloured bowl. Perception 2011, 40:880-882.

17. Piqueras-Fiszman B, Alcaide J, Roura E, Spence C: Is it the plate or is it the food? The influence of the color and shape of the plate on the perception of the food placed on it. Food Qual Prefer 2012, 24:205-208.

18. Ekroll V, Faul F, Niederée R: The peculiar nature of simultaneous colour contrast in uniform surrounds. Vision Res 2004, 44:1765-1786.

19. Hutchings JB: Food colour and appearance. London: Blackie Academic and Professional; 1994

20. Leibowitz H, Myers NA, Chinetti P: The role of simultaneous contrast in brightness constancy. J Exp Psychol 1955, 50:15-18.

21. Maga JA: Influence of color on taste thresholds. Chem Senses Flavor 1974 1:115-119.

22. O'Mahony M: Gustatory responses to nongustatory stimuli. Perception 1983, 12:627-633.

23. Spence C, Levitan C, Shankar MU, Zampini M: Does food color influence taste and flavor perception in humans? Chemosensory Percept 2010, 3:68-84.

24. Piqueras-Fiszman B, Spence C: Crossmodal correspondences in product packaging. Assessing color-flavor correspondences for potato chips (crisps). Appetite 2011, 57:753-737.

25. Spence C: Managing sensory expectations concerning products and brands: Capitalizing on the potential of sound and shape symbolism. J Consum Psychol, 2012, 22:37-54

26. Williams JM: Synesthetic adjectives: A possible law of semantic change. Lanquage 1976, 52:461-478.

27. Wansink B, Cheney MM: Super bowls: serving bowl size and food consumption. J Am Medical Association 2005, 293:1727-1728.

28. Titchener EB: Lectures on the elementary psychology of feeling and attention. New York: Macmillan; 1908.

29. Rolls BJ, Roe LS, Halverson KH, Meengs JS: Using a smaller plate did not reduce energy intake at meals. Appetite 2007, 49:652-660.

30. de Graaf C, Cardello AV, Kramer FM, Lesher LL, Meiselman HL, Schutz HG: A comparison between liking ratings obtained under laboratory and field conditions: the role of choice. Appetite 2005, 44:15-22.

31. Piqueras-Fiszman B, Harrar V, Alcaide J, Spence C: Does the weight of the dish influence our perception of food? Food Qual Prefer 2011, 22:753-756.

32. Ackerman JM, Nocera CC, Bargh JA: Incidental haptic sensations influence social judgments and decisions. Science 2010, '328:1712-1715.

33. Piqueras-Fiszman B, Spence C: The weight of the container influences expected satiety, perceived density, and subsequent expected fullness. Appetite 2012, 58:559-562.

34. Delwiche JF, Pelchat ML: Influence of glass shape on wine aroma. J Sensory Stud 2002, 17:19-28.

35. Hummel T, Delwiche JF, Schmidt C, Hüttenbrink KB: Effects of the form of glass on the perception of wine flavors: A study in untrained subjects. Appetite 2003, 41:197-202.

36. Spence C: Crystal clear or gobbletigook? World Fine Wine 2011, 33:96-101.

37. Ross CF, Bohlscheid J, Weller K: Influence of visual masking technique on the assessment of 2 red wines by trained and consumer assessors. $J$ Food Sci 2008, 73:S279-S285.

38. Fischer U, Loewe-Stanienda B: Impact of wine glasses for sensory evaluation. Int J Vine and Wine Sci, Wine Tasting, Special Edition 1999, 33(Suppl. 1):71-80.

39. Russell K, Zivanovic S, Morris WC, Penfield M, Weiss J: The effect of glass shape on the concentration of polyphenolic compounds and perception of Merlot wine. J Food Qual 2005, 28:377-385.

40. Peynaud E: The taste of wine: The art and science of wine appreciation (Trans. M. Schuster). London: Macdonald \& Co; 1987.

41. Cliff MA: Influence of wine glass shape on perceived aroma and colour intensity in wines. J Wine Res 2001, 12:39-46.

42. Schifferstein HNJ: The drinking experience: Cup or content? Food Qual Prefer 2009, 20:268-276.

43. Guéguen $\mathrm{N}$ : The effect of glass colour on the evaluation of a beverage's thirst-quenching quality. Curr Psychol Lett Brain Behav Cogn 2003, 11:1-6.

44. Krishna A, Morrin M: Does touch affect taste? The perceptual transfer of product container haptic cues. J Consumer Res 2008, 34:807-818.

45. Stern W (Ed): Handbook of package design research. New York: Wiley Interscience; 1981. 
46. Ariely D: Predictably irrational: The hidden forces that shape our decisions. London: Harper Collins Publishers; 2008.

47. Spence, C., \& Piqueras-Fiszman, B. (in press). Dining in the dark: Why, exactly, is the experience so popular? The Psychologist.

48. Spence C, Piqueras-Fiszman B: The multisensory packaging of beverages. In Food packaging: Procedures, management and trends. Edited by Kontominas MG. Hauppauge NY: Nova Publishers; in press.

49. Greenfield H, Maples J, Wills RBH: Salting of food: a function of hole size and location of shakers. Nature 1983, 301:331-332.

50. Gladwell M: The ketchup conundrum: Mustard now comes in dozens of varieties. Why has ketchup stayed the same? In What the dog saw and other conundrums. USA: Little, Brown, \& Company; 2009:32-50.

51. North AC, Hargreaves DJ: The social and applied psychology of music. Oxford: Oxford University Press; 2008

52. Spence C: Wine and music. World Fine Wine 2011, 31:96-104.

53. Stroebele N, De Castro JM: Effect of ambience on food intake and food choice. Nutrition 2004, 20:821-838.

54. King SC, Meiselman HL, Hottenstein AW, Work TM, Cronk V: The effects of contextual variables on food acceptability: A confirmatory study. Food Qual Prefer 2007, 18:58-65.

55. Weber AJ, King SC, Meiselman HL: Effects of social interaction, physical environment and food choice freedom on consumption in a mealtesting environment. Appetite 2004, 42:115-118.

56. Coelho JS, Idlera A, Werle COC, Jansen A: Sweet temptation: Effects of exposure to chocolate-scented lotion on food intake. Food Qual Prefer 2011, 22:780-784

57. Scheibehenne B, Todd PM, Wansink B: Dining in the dark. The importance of visual cues for food consumption and satiety. Appetite 2010, 55:710-713.

58. Yeoh JPS, North AC: The effects of musical fit on choice between two competing foods. Musicae Scietiae 2010, 14:127-138.

59. Spence C, Shankar MU, Blumenthal H: 'Sound bites': Auditory contributions to the perception and consumption of food and drink. In Art and the senses. Edited by Bacci F, Mecher D. Oxford: Oxford University Press; 2011:207-238.

60. Woods AT, Poliakoff E, Lloyd DM, Kuenzel J, Hodson R, Gonda H, Batchelor J, Dijksterhuis GB, Thomas A: Effect of background noise on food perception. Food Qual Prefer 2011, 22:42-47.

61. Massaro DW, Kahn BJ: Effects of central processing on auditory recognition. J Exp Psychology 1973, 97:51-58.

62. Kellaris JJ, Kent RJ: An exploratory investigation of responses elicited by music varying in tempo, tonality, and texture. J Consumer Psychology 1993, 2:381-401.

63. Irmak C, Vallen B, Robinson SR: The impact of product name on dieters' and nondieters' food evaluations and consumption. J Consumer Res 2011, 38:390-405

64. Yorkston E, Menon G: A sound idea: Phonetic effects of brand names on consumer judgments. J Consumer Res 2004, 31:43-51.

65. Yeomans $M$, Chambers $L$, Blumenthal $H$, Blake A: The role of expectancy in sensory and hedonic evaluation: The case of smoked salmon icecream. Food Qual Prefer 2008, 19:565-573.

66. Lee L, Frederick S, Ariely D: Try it, you'll like it: The influence of expectation, consumption, and revelation on preferences for beer. Psychol Sci 2006, 17:1054-1058.

67. Meiselman HL, Bell R: The effects of name and recipe on the perceived ethnicity and acceptability of selected Italian foods by British subjects. Food Qual Prefer 1992, 3:209-214

68. Bell R, Meiselman HL, Barry PJ, Reeve WG: Effects of adding an Italian theme to a restaurant on perceived ethnicity, acceptability, and selection of foods. Appetite 1994, 22:11-24.

69. Wansink B, van Ittersum K, Painter JE: How descriptive food names bias sensory perceptions in restaurants. Food Qual Prefer 2005, 16:393-400.

70. Wansink B: Changing eating habits on the home front: Lost lessons from World War II research. J Public Policy and Marketing 2002, 21 (Spring):90-99.

71. Spence C: The price of everything - the value of nothing? World Fine Wine 2010, 30:114-120.

72. Veale R, Quester P: Do consumer expectations match experience? Predicting the influence of price and country of origin on perceptions of product quality. Int Bus Rev 2009, 18:134-144.
73. Van Ittersum K, Wansink B: Plate size and color suggestibility: the Delboeuf Illusion's bias on serving and eating behavior. J Consum Res, 39. in press.

74. Allison Rl, Uhl KP: Influence of beer brand identification on taste perception. J Marketing Research 1964, 1(3):36.

75. Martin D: The impact of branding and marketing on perception of sensory qualities. Food Sci Technol Today: Proc 1990, 4(1):44-49.

doi:10.1186/2044-7248-1-7

Cite this article as: Spence et al.: Assessing the impact of the tableware and other contextual variables on multisensory flavour perception. Flavour 2012 1:7

\section{Submit your next manuscript to BioMed Central and take full advantage of:}

- Convenient online submission

- Thorough peer review

- No space constraints or color figure charges

- Immediate publication on acceptance

- Inclusion in PubMed, CAS, Scopus and Google Scholar

- Research which is freely available for redistribution 